\title{
Endoscopic needle knife treatment of chronic presacral sinus at the anastomosis at an ileal pouch-anal anastomosis
}

A 63-year-old man presented to the clinic with burning sensation, dyschezia, incomplete evacuation, and increased bowel frequency 1 year after total proctocolectomy and ileal pouch-anal anastomosis (IPAA). A pouch endoscopy showed two conjunct presacral sinuses at the anastomosis ( $\bullet$ Fig. 1 a). The decision was made by the patient, the endoscopist (B. S.), and the colorectal surgeon (D. G.) to perform a therapeutic pouch endoscopy, with surgery as the backup plan. The patient was taken to the outpatient endoscopy suite. After sedation, a GIFH180 gastroscope was applied (Olympus, Tokyo, Japan). Two anastomotic sinuses (both $5 \mathrm{~cm}$ in depth), separated by a septum, were identified. The pouch was otherwise normal. The sinuses were treated with an Olympus triple lumen needle knife (Olympus Medical Systems, Tokyo, Japan) at a setting of endoscopic retrograde cholangiopancreatography (ERCP) endocut on ERBE (USA Incorporated Surgical Systems, Marietta, Georgia, USA) $(\bullet$ Fig. 1 b, c, $\bullet$ Video 1). The entire therapeutic procedure was uneventful and took 10 minutes. The total dose of intravenous meperidine was $100 \mathrm{mg}$ and midazolam $4 \mathrm{mg}$. The patient tolerated the procedure well and had considerable symptom improvement 1 day later. He has been able to maintain his pouch function to date.

Sinus as a form of anastomotic leak occurs in $2.8 \%-8 \%$ of patients undergoing IPAA as a blind-ending track [1-4]. Whether a pouch sinus requires intervention depends on its anatomy and the clinical symptoms. For small sinuses, some surgeons simply delay ileostomy closure and expect spontaneous resolution. Pouch revision and less aggressive methods including transanal unroofing [4] and fibrin glue occlusion [5] have been described. Endoscopic needle knife therapy does not require hospitalization or surgery, and yet

\section{Video 1}

Video demonstration of a new endoscopic technique in which needle knife cutting is used for the sinus.

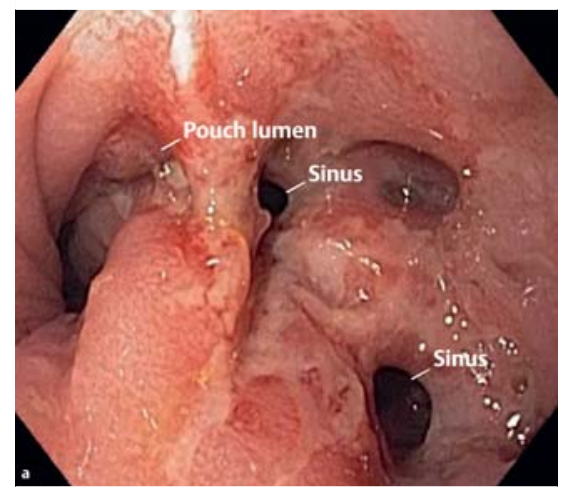

\section{Lian, D. Geisler, B. Shen}

Pouchitis Clinic, Digestive Disease Institute, Cleveland Clinic Foundation, Cleveland, Ohio, USA

\section{References}

1 Akbari RP, Madoff RD, Parker SC et al. Anastomotic sinuses after ileoanal pouch construction: incidence, management, and outcome. Dis Colon Rectum 2009; 52: $452-455$

2 Beart RW. Ulcerative colitis: complications of pelvic pouch. In: Fazio VW (ed). Current therapy in colon and rectal surgery. Toronto: BC Decker, 1990: 180 - 182
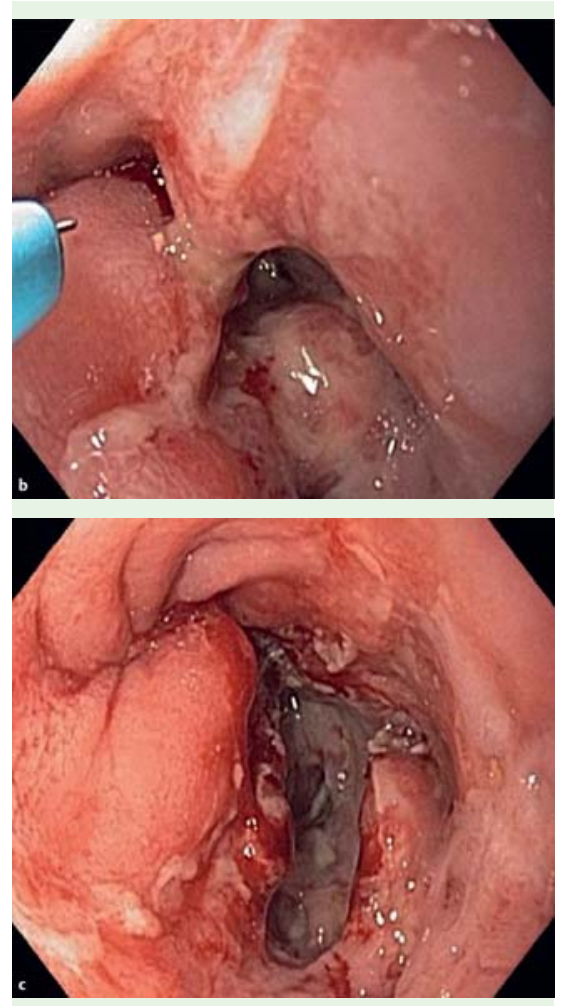

3 Nyam DC, Wolff BG, Dozois RG et al. Does the presence of a pre-ileostomy closure asymptomatic pouch-anastomotic sinus tract affect the success of ileal pouch anastomosis? J Gastrointest Surg 1997; 1: 274-277

4 Whitlow CB, Opelka FG, Gathright JB et al. Treatment of colorectal and ileoanal anastomotic sinuses. Dis Colon Rectum 1997; 40: $760-763$

5 Swain BT, Ellis CN. Fibrin glue treatment of low rectal and pouch-anal anastomotic sinuses. Dis Colon Rectum 2004; 47: 253-255

\section{Bibliography}

DOI $10.1055 / \mathrm{s}-0029-1215257$

Endoscopy 2010; 42: E14

(c) Georg Thieme Verlag KG Stuttgart · New York . ISSN 0013-726X

Corresponding author

B. Shen, MD

Digestive Disease Institute - A31

Cleveland Clinic Foundation

9500 Euclid Ave

Cleveland

Ohio 44195

Fax: +216-444-6305

shenb@ccf.org

Fig. 1 Pouch anastomotic sinus: a before, b during, and $\mathbf{c}$ after endoscopic needle knife therapy.

provides a feasible and effective alternative when spontaneous healing of the symptomatic sinus does not occur. However, this procedure might be limited to relatively small sinus tracts. Large, deep symptomatic sinuses may still require surgical pouch revision or even redo pouch when indicated.

Endoscopy_UCTN_Code_TTT_1AQ_2AJ 